\title{
Saunders's Gull: a new population estimate
}

\author{
L. CAO, M. A. BARTER and X. WANG
}

\section{Summary}

The globally threatened ('Vulnerable') Saunders's Gull Larus saundersi has a small, declining population occupying highly-threatened habitats mainly along the coasts of China, the Korean Peninsula and Japan. The availability of recent count data from key non-breeding regions has provided an important opportunity to re-estimate the species' population size and this is now believed to be a minimum of 14,400 birds, which is more than $70 \%$ higher than the mid-point of the current estimated range $(7,100-9,600)$. However the apparent population increase is almost certainly due to increased survey effort. It is likely that the population is continuing to decline given the significant threats to habitats and high human disturbance levels occurring across the species' range. There are increasing opportunities for coordinated counts of Saunders's Gulls along the Chinese coastline and these data, combined with those being collected annually from other parts of the non-breeding range, should allow improved population estimates to be obtained and the generation of much-needed population trend information.

\section{Introduction}

Saunders's Gull Larus saundersi is a globally threatened species breeding at a few localities on the Yellow Sea coast and spending the non-breeding period along the coastlines of mainland China, Taiwan, Vietnam, the west and south Korean Peninsula and south-western Japan (Figure-1). During the non-breeding season it inhabits intertidal areas and drained coastal fishponds, where it feeds mainly on crabs (BirdLife International 2001). The species is listed as 'Vulnerable' because it has a small population estimate $(7,100-9,600$ individuals [Wetlands International 2006]) which is expected to decline at an increasing rate due to habitat loss and disturbance in the breeding and non-breeding areas (BirdLife International 2007). It is also listed on Appendix I of the Convention on Migratory Species (CMS 2007).

The current population estimate is based on that given in BirdLife International (2001), which was derived from non-breeding season counts conducted during the 1990s. The availability of more recent count data from the non-breeding regions, particularly for mainland China, Taiwan and Japan, provides an important opportunity to review the population estimate for the species.

\section{Methods}

\section{Count timing}

All the count data used for the population estimates were collected during the end-November to late-February period. At this time, gulls should be at their non-breeding locations according to data from Japan, where birds start arriving in mid-October and departure commences in lateFebruary (BirdLife International 2001) and Hong Kong SAR (one of the most southerly nonbreeding locations), where birds commence arriving in early November, numbers build up quickly by mid-November and birds start leaving in late-February (Carey et al. 2001). 


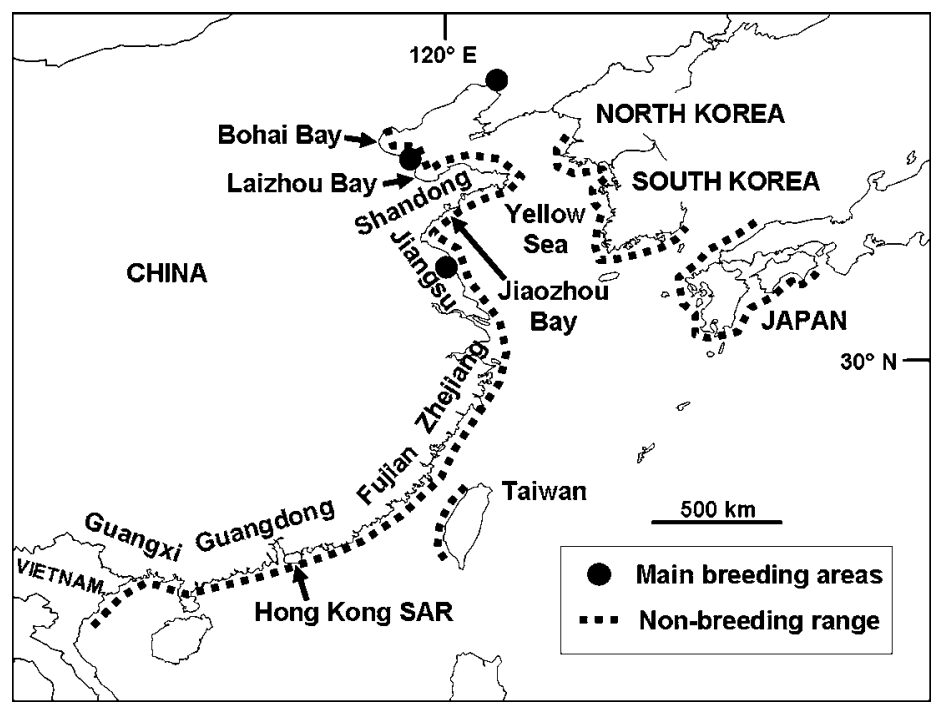

Figure 1. Location of the three main breeding areas (filled circles). The non-breeding range extends south from Bohai Bay along the east and south coasts of China to Vietnam, and along the west and south coasts of the Korean peninsula and south-west coasts of Japan.

\section{Data sources}

Count data obtained during the $2003 / 2004$ to $2006 / 2007$ non-breeding seasons are available for all regions except Vietnam and North Korea, and the southern Chinese provinces of Guangdong, Guangxi and Hainan.

Mainland China: the coasts of Fujian [February 2006] (Barter et al. 2007); Jiangsu [late November 2006], Zhejiang [January 2007] and Shandong [February 2007] (all L. Cao unpub. data); parts of Bohai Bay and Laizhou Bay [December 2005 and February 2006] (Liu et al. 2007); Chongming Island, Yangtze estuary, [January 2007] (Y. Liu in litt.).

Hong Kong SAR: Deep Bay counts [December 2006-February 2007] (HKBWS 2007).

Taiwan: Population estimate from Fang (2005), based on annual counts.

South Korea: Asian Waterbird Census (AWC) count in January 2004 (Li and Mundkur 2007), supplemented by information from N. Moores (in litt.).

Japan: the main Japanese wintering areas in Kyushu, western Honshu and Shikoku [late January-early February 2007] (WWF-Japan 2007; S.I. Hanawa in litt.).

\section{Data analysis}

All the raw count data used in this analysis have resulted from attempts to make complete censuses of Saunders's Gulls in the various survey regions.

In arriving at population estimates for Jiangsu, Zhejiang and Fujian we have adjusted the raw counts to allow for missed birds due to incomplete habitat coverage, but have not allowed for 
undetected birds in surveyed areas. For the other data from China and from Vietnam, for which we had limited knowledge of the count circumstances, we have chosen not to apply corrections to the raw data to allow for incomplete habitat coverage and undetected birds. Thus, most estimates are best described as minimum population estimates (MPEs) and the resulting overall population estimate is a mix of adjusted and unadjusted estimates and will be a conservative estimate of population size. No estimate has been made for North Korea (but see Discussion). All estimates have been rounded to two significant figures.

The bases for each of the regional estimates are explained in the notes to Table 1 .

\section{Results}

Individual estimates for the different regions of Mainland China and other countries and territories in the non-breeding range are given in Table 1 . The minimum Saunders's Gull nonbreeding population is estimated to be approximately 14,400 birds. The China coast (including Hong Kong SAR and Taiwan) is estimated to support a minimum of 10,400 gulls during the nonbreeding season, whilst South Korea and Japan account for another 4,0oo birds. Birds are widely spread in China and occur in good numbers from Bohai Bay southwards to Fujian Province; in South Korea the highest numbers occur on the west coast, especially at Song Do and in the Saemangeum region, and at Suncheon Bay on the south coast (N. Moores in litt.), whilst in Japan the main non-breeding areas are located in the south-west in Kyushu, western Honshu (Chugoku) and Shikoku.

\section{Discussion}

Accurate estimation of a species population size from counts made in different years across a wide geographical range will always be challenging. In practice, this problem is often encountered because comprehensive counts of a widespread population made over a short time frame are logistically difficult, especially in regions such as China, where resources are limited. However, obtaining a satisfactory population estimate is very important as it forms the basis for determining the conservation status of a species, e.g. population trends, identification of important sites and associated threats. We believe the minimum population estimate of approximately 14,400 birds is credible as it is based mainly on data obtained in the JanuaryFebruary period of the two most recent winters for which counts are available (2005-2006 and 2006-2007). In two key areas where count data were not available during these winters, i.e. Taiwan and South Korea, local experts confirm that the estimates accurately reflect current numbers. There is the possibility that changes in distribution along the Chinese coast between years could lead to double-counting; however, it is more likely that the overall underestimation of population numbers in this region will more than outweigh any possible duplication of counts.

No attempt has been made to estimate numbers present in North Korea, but it is probable that Saunders's Gulls occur on the west coast during the non-breeding season as the region has a very large area of intertidal flats (Barter 2002) and lies at a similar latitude to Bohai and Laizhou Bays, which are estimated to hold a combined minimum of 1,500 birds. Counts of this potentially important region should be encouraged; ideally these should also include surveys during the breeding season.

Numbers of Saunders's Gulls appear to have declined in the most southerly part of the range during the last decade, when counts of 70-100 in Hong Kong SAR and 200-300 in Vietnam were recorded in the 1990s (Carey et al. 2001; BirdLife International 2001), whilst large numbers have recently been found in the northernmost part (Bohai Bay) (Liu et al. 2007). It is possible that this apparent change in distribution has resulted from global warming.

Although the MPE is more than $70 \%$ higher than the mid-point of the current estimated range $(7,100-9,600)$, it is unlikely that this apparent increase is due to an actual rise in the population 
Table 1. Minimum population estimates (MPE) for different parts of the Saunders's Gull non-breeding range and counts made during the 2005-2006 and 2006-2007 non-breeding periods.

\begin{tabular}{|c|c|c|c|c|c|}
\hline & \multirow[t]{2}{*}{ MPE } & \multicolumn{2}{|c|}{$2005-2006$} & \multicolumn{2}{|l|}{$2006-2007$} \\
\hline & & Nov-Dec & Jan-Feb & Nov-Dec & Jan-Feb \\
\hline \multicolumn{6}{|l|}{ MAINLAND CHINA } \\
\hline Bohai Bay $^{1}$ & 940 & 864 & 941 & & \\
\hline Laizhou Bay ${ }^{2}$ & 570 & 522 & 569 & & \\
\hline Jiaozhou Bay ${ }^{3}$ & 470 & & & & 2 \\
\hline Jiangsu $^{4}$ & 690 & & & 415 & \\
\hline Yangtze estuary $^{5}$ & 290 & & & & 287 \\
\hline Zhejiang $^{6}$ & 4,500 & & & & 3,639 \\
\hline Fujian $^{7}$ & 2,100 & & 1,574 & & \\
\hline Guangdong/Guangxi/Hainan ${ }^{8}$ & 65 & & & & \\
\hline Mainland China total & 9,625 & & & & \\
\hline HONG KONG SAR ${ }^{9}$ & 35 & & & & 35 \\
\hline TAIWAN $^{10}$ & 700 & & & & \\
\hline VIETNAM $^{11}$ & 10 & & & & \\
\hline SOUTH KOREA $^{12}$ & 2,000 & & & & \\
\hline $\mathbf{J A P A N}^{13}$ & 2,000 & & 1,955 & & 1,575 \\
\hline GRAND TOTAL & 14,370 & & & & \\
\hline
\end{tabular}

Notes: All estimates have been rounded to two significant figures.

${ }^{1}$ The two counts were from the Tanggu-Dagang region of Tianjin Municipality (Liu et al. 2007); Liu et al. (2007) note that there are numerous unsurveyed areas of inter-tidal mudflat elsewhere in Bohai Bay and that it is likely that other gull concentrations occur within the bay.

${ }^{2}$ Survey covered only part of Laizhou Bay which has very extensive mudflats, many of which are difficult to survey (Liu et al. 2007; pers. obs.);

'In February 2007 we saw 'hundreds' of what were almost certainly Saunders's Gulls in Jiaozhou Bay but were unable to confirm this due to the long viewing distance; 472 were seen there in December 2002 (Liu et al. 2007); although there are large numbers of gulls around the Shandong Peninsular coastline (pers. obs.), we saw only two Saunders's Gulls in the region;

${ }^{4}$ Estimate based on our count of 415 birds when an estimated $60 \%$ of the available habitat was covered; 1,257 birds were counted in the 1997-1998 winter (Huo et al. 2000) and 1,040 in the 2002-2003 winter (Zhang 2003); ${ }^{5}$ Based on a count of 287 birds on the north coast of Chongming Island in late-January 2007 (Y. Liu in litt.); ${ }^{6}$ Estimate based on our count of 3,639 birds when an estimated $80 \%$ of the available habitat was covered; counts of 2,974 were made during December 1997 and 4,686 in January 1999 (Huo et al. 2000), and 1,335 in the 20022003 winter (Zhang 2003);

${ }^{7}$ Estimate based on our count of 1,574 birds when an estimated $75 \%$ of the available habitat was covered; counts of 401 were made during December 1997- January 1998 (Huo et al. 2000), and 231 in the 2002-2003 winter (Zhang 2003);

${ }^{8}$ Most recent published counts are of 60 birds in Guangdong and four in Guangxi (Huo et al. 200o);

${ }^{9}$ Average of three counts during 2006-2007 winter (HKBWS 2007);

${ }^{10}$ Estimate of 700 from Fang (2005), which states that numbers in recent years ranged from 60o-830; confirmed to be a good current estimate (W. Liu in litt.);

${ }^{11}$ Nine birds recorded during the most recent Asian Waterbird Census count in 2002 (Li and Mundkur 2007);

${ }^{12}$ Based on estimate that number is c. 2,000 (N. Moores in litt.); 1,853 counted during Asian Waterbird Census 2004 survey;

${ }^{13}$ Estimate of 2,000 (S.I. Hanawa in litt.) based on single day counts of 1,841 (January 2005), 1,955 (January 2006) and 1,570 (January 2007), which did not cover some small known Saunders's Gull sites.

size: it is far more likely a result of increased survey effort. In fact, it is highly probable that numbers of Saunders's Gulls are decreasing as coastal wetlands within the species range are suffering greatly from land claim, pollution and human disturbance (Barter 2002; UNEP 2005a, 2005 b). Additionally, changes in river flows as a result of water extraction and damming may be 
significantly affecting sediment and nutrient inputs to coastal areas, with a consequent effect on biological productivity and intertidal area extent (Zhu et al. 2003; Yang et al. 2007). Thus, the prediction that the rate of population decline is likely to increase in the future (BirdLife 2007) is probably correct.

When allowances are made for the likelihood that numbers on the Chinese coast are higher than estimated and that birds occur in North Korea during the non-breeding season, it is probable that the actual population is larger than estimated here. With the recent increase in the number of local ornithological societies in China, many of which are located in coastal cities, it is to be hoped that coordinated counts can be conducted of the main Saunders's Gull sites along the Chinese coastline. These data, along with those being collected annually in Taiwan, Hong Kong SAR, South Korea and Japan (and hopefully from North Korea in the future), should allow further improvements in the population estimate to be achieved and generation of the critically important population trend information for this globally threatened species.

\section{Acknowledgements}

The majority of the Chinese field surveys were supported by the National Natural Science Foundation of China (Grant Nos. 30570253 and 30770313); data were also collected during shorebird surveys funded by the US Fish and Wildlife Service (Contract No. 70181-6-M440). We also thank WWF HK and the Fujian Forestry Bureau for arranging and funding the Fujian coast survey. We are grateful to two anonymous referees who provided very useful suggestions to improve the paper.

\section{References}

Barter, M. A. (2002) Shorebirds of the Yellow Sea-importance, threats and conservation status. Canberra, Australia: Wetlands International. Global Series 9, International Wader Studies 12.

Barter, M. A., Yu, X., Cao, L., Liu, B. F., Yang, Z. L. and Zheng, D. T. (2007) Wintering waterbird survey of the coastline of Fujian Province, China: 8-27 February 2006. Beijing: China Forestry Publishing House.

BirdLife International (2001) Threatened birds of Asia: International Red Data Book. Cambridge, UK: BirdLife International.

BirdLife International (2007) Species factsheet: Larus saundersi. http://www.birdlife.org (accessed 10 November 2007).

Carey, G. J., Chalmers, M. L., Diskin, D. A., Kennerley, P. R., Leader, P. J., Leven, M. R., Lewthwaite, R. W., Melville, D. S., Turnbull, M. and Young, L. (2001) The Avifauna of Hong Kong. Hong Kong: Hong Kong Bird Watching Society.

CMS (2007) Appendix I of the Convention on the Conservation of Migratory Species of
Wild Animals. www.cms.int/documents/ appendix/cms_appı_2.htm\#appendix_I (accessed 1o November 2007).

Fang, W. H. (2005) Guide to the threatened birds of Taiwan. Taipei: Owl Publishing House (in Chinese and English). ISBN-10: 9867415817.

HKBWS (2007) Hong Kong Bird Watching Society monthly waterbird counts. http:// www.hkbws.org.hk/waterbird/monthc.html (accessed 10 November 2007).

Huo, Y. Q., Chu, G. Z., Qian, F. W., Lu, J. and Dai, M. (2000) The distribution and population of the Saunders's Gull at the eastern coast of China. Pp. 214-218 in Studies on Chinese Ornithology. Proceedings of the $4^{\text {th }}$ Ornithological Symposium of Mainland and Taiwan, China. China Ornithological Society, Wild Bird Society of Taipei and China Wildlife Conservation Association. Beijing: Forestry Publishing House.

Li, Z. W. D. \& Mundkur, T. (2007) Numbers and distribution of waterbirds and wetlands in the Asia-Pacific region. Results 
of the Asian Waterbird Census: 20022004. Kuala Lumpur, Malaysia: Wetlands International.

Liu, Y., Holt, P. and Zhang, Z. W. (2007) Wintering records of Saunders's Gull in Bohai Bay, China. J. Yamashina Inst. Ornithol. 38: 100-103.

UNEP (2005a) Qu, J., Xu, Z., Long, Q., Wang, L., Shen, X., Zhang, J. and Cai, Y. East China Sea. GIWA Regional Assessment 36. Kalmar, Sweden: University of Kalmar.

UNEP (2005b) Wilkinson, C., DeVantier, L., Talaue-McManus, L., Lawrence, D. and Souter, D. South China Sea. GIWA Regional Assessment 54. Kalmar, Sweden: University of Kalmar.

Wetlands International (2006) Waterbird population estimates - Fourth Edition. Wageningen, The Netherlands: Waterbirds International.
WWF-Japan (2007) The interim report of the shorebird census in Japan (Winter 2006-07). Tokyo: WWF-Japan.

Yang, S. L., Zhang, J. \& Xu, X. J. (2007) Influence of the Three Gorges Dam on downstream delivery of sediment and its environmental implications, Yangtze River. Geophys. Res. Lett. 34, L10401, doi:10.1029/2007GL029472.

Zhang, G. G. (2003) Survey on wintering Black-faced Spoonbill and Saunders's Gull in the coastal areas of southeast China. China Crane News 7: 30-31.

Zhu, Z., Cai, X., Giordano, M., Molden, D., Hong, S., Zhang, H., Lian, Y., Li, H., Zhang, X. and Xue, Y. (2003) Yellow River comprehensive assessment: Basin features and issues. Colombo, Sri Lanka: International Water Management Institute. Working Paper 57.

L. CAO*, X. WANG

School of Life Sciences, University of Science and Technology of China, 96 Jinzhai Road, Hefei 230027, Anhui, China.

M. A. BARTER

21 Chivalry Avenue, Glen Waverley, Vic 3150, Australia.

${ }^{*}$ Author for correspondence; e-mail:caolei@ustc.edu.cn

Received 11 November 2007; revision accepted 5 February 2008 